\title{
THE TAXONOMY OF EDUCATIONAL OBJECTIVES: AN EVALUATION OF THE LEARNING DOMAINS
}

\section{IYA GANA ALIYU; YUSUF ISMA'IL \& MUKHTAR ALHAJI LIMAN}

\begin{abstract}
The role of taxonomy of education in formal educational sustem cannot be over-emphasized; as such the paper examines the concept of learning domains which include: cognitive domain. affective domain and psychomotor domain in curriculum contents delivery. The role of teachers in the utilization and achualization of the three leaming domains in reaching and leaming which involves proper and effective selection of the appropriate key nords (verbs) for the statement of behavioral objectives, choice of the past learning experiences of leamers and the effective usage of instructional media for the attainment of instructional objectives of a lesson in which many teachers' more especially prospective teachers' face with these challenges. The authors also suggest that for effective teaching and leaming to prevail in any formal educational system. teachers being the implementers of schools' curriculum should imbibe and enact the tatonomy of educational objectives in teaching and leaming encounter for a better achievement of instructional objectives by embracing the following strategies such as: teachers' mastery of their subject-matter, effective utilization of leamers past experiences and proper selection, appropriateness and usage of instructional media, all of which could be attained through attending of educational programs like short-courses, refresher workshops, symposiums, seminars and conferences.
\end{abstract}

Key words: Taxonomy, Educational objectives and Learning domains

\section{INTRODUCTION}

The role of taxonomy of educational objectives in teaching and learning encounter cannot be over-emphasized. As such; in an attempt to justify teaching and learning within the frame-work of effective utilization of the popularly known Bloom taxonomy of educational objectives, the authors find it necessary to preamble the two concepts of education fundamental. These are "Curriculum" and "taxonomy of educational objectives". Whenever we talk about curriculum the term "Education" will be sprinkled throughout the conversation. This is because the main purpose of education is to socialize an individual and groups to become better members of community so as to contribute their quarter towards a better society. This process can only be actualized and materialized if proper construction and implementation of a formal school curriculum is well executed. Furthermore, it has been a global trend even right from beginning of human society as the main objective of education, be it formal or informal has always been the transmission of accumulated experience of people and their culture, so as to fit into a membership of community or society, he/she has belong.

Therefore, going by this assertion, the term curriculum seems to be a difficult concept to be defined and this is because, there is no universally accepted definition of the term "curriculum" and more so, it has different perspectives to different categories of individuals. But from a more general perspective. the term curriculum is derived from the 
Latin word "Currus" which means running course; it is like athletic track and field events, such as 200 meters or 400 meters running course and it has been defined as all the learning of students which is planned by and directed by the school to attain its educational goals, (Clark, 2009). To expatiate on this definition. schools' curriculum most takes cognizance of learners as the most central elements. All of the learning of students" can be considered to represent both content and learning experience that the students are exposed in the school. James, (2006) also defined curriculum as the planned and guided learning experiences and intended learning outcomes, formulated through systematic reconstruction of knowledge and experiences. In a broader perspective curriculum is more than putting together a set of academic required subjects. It must consider all aspects of the learners life, the learning need of learners, the time available for the session and the teacher's idea, capability and subject-matter background and all others interpersonal skills that will better instruction taking, (Ngada, 2008) .

Then, what is taxonomy of educational objectives? Taxonomy of educational objectives usually refers to the three learning domains in education and learning is usually occurring in every bit of one's life, consciously or unconsciously. For example, one can learn mental skills, develop attitudes and acquire new physical skills in the course of performing our daily activities for our daily live. These daily activities therefore involve the three domains of learning. which includes cognitive domain (knowledge). affective domain (attitudes) and psychomotor domain (skills). The domains of knowledge can take place within frame-work of a proper dissemination of the entire processes by teachers in order to transfer knowledge, attitude or skills to learners. However, the domains of knowledge is centered on looking into the goals of learning process, that is to say, after a learning episode, the learner is expected to have acquired new skills, knowledge or attitudes.

Therefore, this paper critically examines the three learning domains founded by Benjamin Bloom (1956), which comprise of the following: "Cognitive", "affective" and "psychomotor" domains. In addition to the categories of each domain, give relevant examples on each component of the learning domains and enumerating a number of verbs that can be used by teachers for effective teaching and learning processes.

\section{THE DOMAINS OF KNOWLEDGE}

Even though, there are different ways and techniques of knowledge acquisition, but for the purpose of this paper Benjamin Bloom taxonomy, (1956) of educational objectives is considered and identified three domains of educational activities as follows:

- Cognitive: Mental skills (knowledge)

- Affective: growth in feelings or emotional areas (attitudes)

- Psychomotor: Manual or physical skills (skills)

Domains can be thought of as categories whereby trainers refer to these three categories as (KSA) which means $\mathrm{K}=$ knowledge, $\mathrm{S}=$ skills and $\mathrm{A}=$ attitude. Taxonomy of educational objectives 
usually deal with learning behavior and goals of the learning process which is also referred to as learning outcome of certain concepts in formal educational setting.

\section{COGNITIVE DOMAIN}

The cognitive domain Bloom, (1956) involves the development of mental skills and the acquisition of knowledge. This includes: the recall or recognition of specific facts. procedural patterns, and concepts that serve in the development of intellectual abilities and skills of an individual or groups of learners. Cognitive domain focuses on intellectual skills development based on the following components: knowledge, comprehension, application, analysis synthesis and evaluation, (Krathwohl, Bloom, \& Masia, 1973). It is frequently used to describe the increasing complexity of cognitive skills of learners. The components can be thought of as degrees of difficulties that is, the first one must normally be mastered before the next ones can be taken. Therefore, the six categories of cognitive domain of the taxonomy of educational objectives can be explained with examples and key words (verbs) in a more precise and concise ways.

\section{S/NO. COMPONENTS}

1.

Knowledge: recall data or
information

2. Comprehension: understand the meaning, translation. interpolation. and interpretation of instruction and problems. State a problem in one's own words

3. Application: Use a concept in a new situation or unprompted use of an abstraction. Applies what was learned in the classroom into novel situation in the work place

4. Analysis: Separates materials or concept into component parts so

\section{EXAMPLES AND KEY WORDS} (VERBS)

Examples: recite a policy, quote prices from memory to a customer.

Key words: Define, describe, identify, label, list, match, name outline, recall, recognize, reproduce, select, state etc.

Example: rewrites the principles of test writing. Explain in one's own words the steps for performing a complex task. Translate an equation into a computer spread sheet

Key words: comprehend, convert, defend, distinguish, estimate, explain, extend, generalize, give an exarnple, infer, interpret, paraphrase, predict, rewrite, summarize translate etc

Examples: Use a manual to calculate an employer's vacation time. Apply laws of statistics to evaluate the reliability of a written text.

Key words: apply, change, compute, construct, demonstrate, discover, manipulate modify, operate, prepare, produce relate, show, solve, use etc.

Example: troubleshoot a piece of equipments by using logical deduction. 
that its organizational structure may be understood. Distinguishes between facts and inferences

5. Synthesis: Builds a structure or pattern from diverse elements. Put parts together to form a whole, with emphasis on creating a new meaning or structure
6. Evaluation: Make judgments about the value of ideas or materials

recognize logical fallacies in reasoning. Gather information from a department and select the required tasks for training. Key words: Analyze, break down. compare, contrast, differentiate, discriminate, distinguish, identify, illustrate. infer. outline. relate. select. separate etc.

Example: write company operations or process manual. Design a machine to perform a specific job. Integrate training from several sources to solve a problem. Revise and process to improve the outcome.

Key words: categorize, combine, compile, compose, create, devise, design, explain, generate, modify, organize, plan, arrange, reconstruct, relate reorganize, revise, rewrite, summarize, re-tell, etc.

Examples: Select the most effective solution, Hire the most qualified candidate. Explain and justify a new budget

Key words: Appraise, compare, conclude, contract, criticize, critique, defend, describe, discriminate, evaluate, explain, interpret, justify, relate, summarize, support etc.

Source: Krathwohl, Bloom, \& Masia, (1973) and Clark, (2009).Bloom's Taxonomy of $L . D$.

\section{AFFECTIVE DOMAIN}

The affective domain is critical for learning but is often not specifically addressed and is the domain that deals with attitudes, motivation, willingness to participate, valuing what is being learned, and ultimately incorporating the values of a discipline into a way of life. The stages are not as sequential as the cognitive domain, but have been described from the simplest behavior to the most complex one.

\begin{tabular}{ll}
\hline S/NO. & COMPONENTS \\
\hline 1. & $\begin{array}{l}\text { Receiving phenomena: Awareness, } \\
\text { willingness to hear, selected } \\
\text { attention }\end{array}$
\end{tabular}

EXAMPLE AND KEY WORDS (VERBS)

Examples: listen to others with respect. Listen to and remember the names of newly introduced people.

Key words: ask, choose, describe, follow. give, hold, identify, locate, 
name, point to, select, erect, reply, use etc

2. Responding to phenomena: Active participation on the part of the learners. Attends and reacts to particular phenomena. Learning outcomes may emphasize compliance in responding, willingness to respond on satisfaction in responding (motivation)

Example: participates in class discussions, gives a presentation. Question new ideals, concepts, models, etc in order to fully understand them, know the safety rules and practice them.

Key words: answer, assist, aids comply, conform. discuss, create, help, label, perform, practice, present, read, recite, report, select, tell, write etc

3. Valuing: the worth or value a person attaches to a particular object, phenomenon, research behavior. This ranges from simple acceptance to the more complex state of commitment. Valuing is based on the internalization of a set of specified values, while clues to those values are expressed in the learner's overt behavior and are often identifiable.

5. Organization: organizes values into priorities by contrasting different values resolving conflicts between them, and creating a unique value system. The emphasis is on comparing, relating and synthesizing values.

6. Internalizing

values: (characterization) has a value Example: Demonstrates belief in the democratic process. Is sensitive towards individual and cultural differences (value diversity) shows the ability to solve problems. Proposes a plan to social improvement and follows through with commitment. Informs management on matters that one feels strongly about.

Key words: completes, demonstrates, differentiates, explains, follows, forms, initiates, invites, joins, justifies, proposes, reads, reports, selects, shares, studies, works etc.

Examples: recognizes the need for balance between freedom and responsible behavior. Accepts responsibility for one's behavior. Explains the role of systematic planning in solving problems. Accepts professional ethical standards. Creates a life plan in harmony with abilities, interests, and beliefs, priorities time effectively to meet the needs of the organization, family and self.

Key words: Adheres, alters, arranges, combines, compares, completes, defends, explains, formulates, generalizes, identifies, integrates, modifies, orders, organizes, prepares, relates synthesizes. system that controls their behavior. group activities (displays team work). 
The behavior is pervasive, Uses an objective approach in problem consistent, predictable, and most solving. Displays a professional importantly, characteristics of the commitment revises judgments and learner. Instructional objectives are changes behavior in light of new concerned with the students' general evidence. Values people for what they patterns of adjustment (personal, are, not how they look.

social, emotional).

Key words: Acts, discriminates, displays, influences, listens, modifies, performs, practices, proposes, qualifies, questions, revises, serves, solves, verifies.

Source: $\quad$ Krathwohl, Bloom, \& Masia, (1973) and Clark, (2009).Bloom's Taxonomy of $L . D$.

\section{PSYCHOMOTOR DOMAIN}

Psychomotor domain focuses on performing sequences of motor activities to a specified level of accuracy, smoothness, rapidity, or force. According to Simpson, (1972) psychomotor domain includes: physical movement, co-ordination and use of the motor-skills areas and the development of these skills requires practices and it is measured in terms of speed, precision, distance, procedures, or techniques in execution. The seven major categories are giving below from the simplest behavior to the most complex one.

\section{S/NO COMPONENTS}

EXAMPLE AND KEY WORDS (VERBS)

1. Perception: Is the ability to use
sensory cues to guide motor
activity. This ranges from
sensory stimulation, through cue
selection, to translation

2. Set: readiness to act, it includes mental, physical and emotional sets. These three sets are dispositions that predetermine a person's responses to different situations (sometimes called mind sets)
Example: Detects non-verbal communication cues estimate where a ball will land after it is thrown and then moving to the correct location to catch the ball. Adjusts heat of store to correct temperature by smell and taste of food. Adjusts the height of the forks on a forklift by comparing where the forks are in relation to the pallet.

Key words: chooses, describes, detects, differentiates, distinguishes, identifies, isolates, relates, selects.

Example: knows and acts upon a sequence of steps in a manufacturing process. Recognize one's abilities and limitations. Shows desire to learn a new process, (motivation). Note: This subdivision of psychomotor is closely related with the "responding to phenomena" subdivision of the affective domain.

Key words: begins, displays, moves, proceeds. and reacts. shows, states, volunteers. 
3. Guided response: The early stages in learning complex skills that includes imitation and trial and error. Adequacy of performance is achieved by practicing

4. Mechanism: This is the intermediate stage in learning a complex skills, leaner responses have becomes habitual and the movements can be performed with some confidence and proficiency

5. Complex overt responses: The skilful performance of motor acts that involve complex movement patterns, proficiency is indicated by a quick, accurate, and highly coordinated performance, requiring a minimum of energy. This category includes performing without hesitation, and automatic performance

6. Adaption: Skills are well developed and the individual can modify movement patterns to fit special requirement

7. Origination: creating new movement patterns to fit a particular situation or specific problems. Learning outcomes emphasize creativity based upon highly developed skills
Example: performs a mathematical equation as demonstrated. Follows instruction to build a model responds hand-signals of instructor while learning to operate a fork life.

Key words: copies, traces, follows, react

Examples: Use a personal computer, repair a leaking faucet. Drive a car

Key words: Assembles calibrates, constructs, dismantles, displays, fastens, fixes, grinds, heats, manipulates, measures, mends, mixes, organizes sketches

Examples: maneuvers a car into a tight parallel parking spot. Operates a computer quickly and accurately. Displays competence while playing the piano.

Key words: assembles, builds, calibrates, constructs, dismantles, displays, fastens, fixes, grinds, heats, manipulates, measures, mends, mixes, organizes, sketches etc.

Examples: responds effectively to un-expected experiences. Modifies instruction to meet the needs of the learners. Perform a task with a machine that it was not originally intended to do (machine is not damaged and there is no danger in performing the new task).

Key words: adapts, alters, changes, resistancearranges, reorganizes, revises varies.

Example: constructs a new theory, develops a new and comprehensive training program. Creates a new gymnastic routine

Key words: Arranges, builds, combines, composes, constructs, creates, designs, initiates, makes, originates

Source: $\quad$ Krathwohl, Bloom, \& Masia, (1973) \& Clark, (2009).Bloom's Taxonomy

\section{CHALLENGES $\quad$ ASSOCIATED WITH LEARNING DOMAINS}

There are numerous challenges distressing the attainment of the learning domains and these include: teachers instructional objectives key words (verb): choosing ability, mastery of the subject-matter, appropriateness in selection of past learning experiences and selection, usage of effective instructional media. Teachers' usually 
encounter difficulties in selection of appropriate key words (verbs) in writing lessons' statement objectives, teachers' should note that statement objectives of teaching of a lesson are distinct from the teaching and learning aims and goals, (Ornstein \& Hunkins. 1978). Objectives of a lesson sometimes called specific behavioral objectives are those intended and immediate teaching and learning feedback that a teacher is design to attain within a frame-work of a specific topic and time. While aims and goals of teaching and learning are relatively lie within the frame-work of a long term plan and attain in progression after a span of period of time,( Ornstein \& Hunkins, 1978).

Mastery of the subject-matter is crucial to the teaching profession. This is because without mastery of the specialized field to which a teacher is teaching causes a lot of havoc such as: loss of teacher personality, lack of confidence and above all mischief and misguide. Inability to select appropriate teaching and learning experiences and learning encounters stand to be a great challenge to teachers. Teachers usually thought that past learning experiences/previous knowledge are those immediately taught topics in a lesson. But previous knowledge or past experiences of a learner refer to those accumulated experiences not necessarily preceding a topic to be taught and also not necessarily taught in formal educational setting that seem to be appropriate and relevant in aiding the acquisition of either skills or knowledge of the lesson/topic at hand. Teachers, more especially prospective teachers usually encounter difficulties in selection and justification of appropriateness of the learning experiences that could facilitate the desired teaching and learning outcomes, (Tyler, 1949). For example, learners' past experiences attained in the course of interaction with their environments can effectively stand to be a background for building new experiences on and not necessarily what is being taught in classroom.

Another issue of utmost concern is the use of instructional media and other relevant teaching aids: such as pictures, images and diagrams and relevant methodologies of teaching such as: dramatization, demonstration and group discussion in conveyance of desirable teaching and learning outcomes. Lack of appropriate selection and usage of these media seems to pose commotion to teaching and learning processes. These commotions include: mislead, misplacement of priority, vagueness and misguidance, (Ornstein \& Hunkins, 1978). Many teachers, most especially prospective teachers find it difficult to appropriately select and use instructional media and appropriate teaching method in their teaching. It was also noted from the experiences and encounters with prospective students' teaching practice supervision which was an integral part of the teaching profession that apart from having difficult in selection appropriate instructional media and teaching methodology, they also had difficulty in improvising teaching aids that could facilitate teaching and learning processes.

\section{RECOMMENDATIONS}

Teaching and learning is no doubt a two ways encounter, being a process of teaching and acquisition of knowledge or experience, there is usually a teacher who is a custodian of transferring the 
knowledge and a learner whom the knowledge is been tiansferred to. In view of the above, we shall give some guidelines to teachers and learners that will enable them achieve the desired learning objectives, aims and goals. Teachers must learn to appropriately choose behavioral objectives key words (verbs). Teachers should avoid the use of verbs such as: "to know" and "to understand" in stating specific behavioral objectives of a lesson. Instead, it should be used in outlining the achievement of the broad intended teaching and learning outcomes. Mastery of teachers' subject-matter is paramount to the teaching profession. Successful teaching and learning usually occur based on "teachers' mastery of the subject-matter", as such teachers' should always be keen in updating their knowledge, through attending of courses, refresher workshops, symposiums, seminars and conferences.

Learners' past experiences or previous knowledge trigger the learning of a topic to be taught, as such teachers' should scout relevant experiences that could aids the teaching and learning of the topic at hand. Teachers' should inquire from the learners their previous knowledge about the subject taught and their understanding on the topic to be taught before breaking the subject matter from simple to complex form (Tyler, 1949). This will serve as the basis for a better understanding of the concept/topic and on the same vein will enable learners to recall, identify, name, list, imitate, recite, or build on what they might have learned in relation to their interaction with global world.

Furthermore, teachers' should imbibe the use of instructional media and other relevant teaching aids such as pictures, images, diagrams, etc and also methods like dramatization, demonstration, and group discussion in inculcating the desired knowledge in order to achieve the main objectives of the lesson. Teachers' role is to help the learners to differentiate facts like objects, images, etc for example, differentiating between living and non-living things. Use of practical, experiments, field trips, enable the learners to understand the topic being taught that is putting theory into practice.

\section{Conclusion}

The paper examined the three learning domains and the role of teachers towards effective utilization of the three learning domains. The three learning domains are very essential in the teaching learning process. This is to say teachers need to familiarize themselves with the various components of the three learning domains, as such, that will enable them to function effectively in the discharge of their noble duty of imparting knowledge to the group of learners. Teacher as a commander-in-chief of the class, must supervises all given tasks to the learners for effective realization and actualization of the desired teaching and learning outcomes. Teaching and learning processes should gear towards effective teaching and learning approach rather than teacher-centered approach, as such, that will make the encounter more meaningful and productive to both individual and group of learners.

\section{REFERENCES}

Bloom, B. S. (1956). Taxonomy of educational, objectives, handbook 
on cognitive domain. New York. David McKay Co. INt.

Clark, D. R. (2009). Bloom's Taxonomy of Leaning Domains. Retrieved $<$ on $3^{\text {rd }}$ June, http://www.experimentresources.com/ $>$

James, N. A. (2006). Issues in Curriculum Development. Published by Kolas Printing, Co., Lagos.

Krathwohl, D.R., Bloom, B. S. \& Masia, B. B. (1973). Taxonomy of educational objectives, the classification of educational goals. Hand book II: affective domain. New York, McKay Co.

Ngada, A. J. (2008). Issues in Curriculum Development. $2^{\text {nd }}$ ed. Lagos: T-Richard.

Ornstein A. C., \& Hunkins F. P. (1978). Curriculum: Foundation, Principles, and Issues, third edition. Allyn and Bacon. Aviacom company 160 Gould street Needham Heights, MA 02194.

Simpson, E. J. (1972). The classification of educational objectives in the psychomotor domain. Washington, DC. Gryphon House.

Tyler, R. W. (1949). Basic Principles of Curriculum and Instruction. University of Chicago Press. Chicago and London. 